\title{
Expressão gênica de TLR-2, TLR-4, HMGB1 e VEGF em úlceras abomasais em bovinos de corte
}

Leonardo Aparecido Teixeira Bentin;, Fernando Christiano Gabriel Morelli, Priscila Dalmagro, Gisele Fabrino Machado, Flavia Lombardi Lopes, Francisco Leydson Formiga Feitosa, Luiz Claudio Nogueira Mendes, Juliana Regina Peiró

Faculdade de Medicina Veterinária, Universidade Estadual Paulista (UNESP), Araçatuba, São Paulo, Brasil

*Autor correspondente

e-mail: alt_leonardo@hotmail.com

\section{Resumo}

As úlceras abomasais atingem bovinos em todos os sistemas de produção, causando perdas econômicas. As erosões abomasais são classificadas em quatro categorias (grau 1-4). Em camundongos, a proteína do grupo de alta mobilidade 1 (HMGB1), os receptores Toll-like (TLR)-2 e -4 e o fator de crescimento endotelial vascular (VEGF) estão envolvidos no processo de reparação da úlcera. O objetivo foi investigar a presença de HMGB1, TLR-2, -4 e VEGF em úlceras abomasais de bovinos de corte. Foram utilizados abomasos bovinos obtidos em abatedouro comercial. Os tecidos foram coletados e classificados macroscopicamente e por histopatológica para a caracterização da lesão. 0 mRNA foi isolado a partir de $30 \mathrm{mg}$ de tecido. A integridade e a quantidade de mRNA, verificados através do espectrofotômetro. A expressão dos genes foi medida através da RT qPCR, utilizado o GAPDH e $\beta$-actina como genes housekeeping. Os dados foram submetidos à análise de variância, seguida pelo teste F. As médias, comparadas pelo teste de Bonferroni $(\mathrm{P}<0,05)$. A classificação macroscópica dos grupos (controle, úlcera de Grau 1 e úlcera de Grau 2) correspondeu às características histopatológicas descritas anteriormente (ASAAD, 2014). A expressão de HMGB foi semelhante entre os grupos $(P=0,341)$. As úlceras de Grau 2 apresentaram uma expressão duas vezes maior de TLR-2 $(\mathrm{P}=0,019)$ em relação às úlceras de Grau 1. Os três grupos apresentaram expressão gênica semelhante de TLR-4 e VEGF (P = 0,598 e P = 0,393, respectivamente). O TLR-2 é expresso em várias células, incluindo as do trato gastrointestinal (TGI) e desempenha importante função de proteção da barreira mucosa. 0 aumento da expressão de TLR2 nas úlceras de Grau 2 em relação àquelas de Grau 1, demonstrou comportamento semelhante à mucosa do intestino delgado de humanos e recrutamento de infiltrado inflamatório mononuclear e neutrófilo. A inalteração da expressão de HMGB1 nos tecidos ulcerados em relação aos normais pode ser decorrente da pequena destruição tecidual observada nos dois tipos de úlcera analisados, confirmado à histopatologia. 0 aumento da expressão de HMGB1 tem sido relatado no TGI em decorrência da disfunção da barreira de 
proteção. Como consequência da necrose tecidual estar restrita a pequenas áreas e do acelerado processo de cicatrização local, não foi necessário alterar a expressão de VEGF nos tecidos ulcerados para estimular a cicatrização da mucosa abomasal. A maior expressão de TLR-2 em úlceras de Grau 2 provavelmente está ligada à estimulação da cicatrização local. Entretanto, a presença da expressão de TLR-4, HMGB1 e VEGF demonstra que estes genes participam da resposta cicatricial recrutando infiltrado inflamatório mononuclear e neutrofílico no compartimento abomasal. 